\title{
Study of a protein based angiogenic profile in endometrial tissue of women undergoing assisted reproductive techniques - A pilot study
}

Background: Infertility is a common condition nowadays affecting about 10 to 15 percent of reproductive-aged couples. It is defined as the failure to achieve pregnancy after 12 months or more of regular unprotected intercourses. Infertility treatment is a complex process influenced by numerous factors. Recent advances in assisted reproduction techniques (ART) have provided effective treatment for infertile couples. A large number of independed factors seem to be associated with the success outcome of ART. The aim of this study is to detect the role of angiogenenic factors in endometrial tissue of women who underwent ART.

Methods: Eight samples of endometrial tissue from women who underwent ovarian stimulation were analyzed using the Proteome ProfilerTM Human Angiogenesis Array Kit, screening for the presence of 55 soluble angiogenesis-related factors. For the analysis of array's results, PCA procedure and Mann-Whitney U test ware used.

Results: A protein profile based on the expression of a subset of 7 factors could separate the 8 women in 2 groups. Among the group of the 4 patients with the higher expression of the 7 combined factors, 2 pregnancies were observed, while in the other group with the lower expression only a biochemical pregnancy was observed. These findings showed that the expression of angiogenic factors is strongly collerated with pregnancy.

Conclusion: In conclusion, we developed an "angiogenic profile" for patients who underwent ovarian stimulation, based on the combination of 7 angiogenic factors, which can be used, after appropriate validation, as a prognostic marker for ART outcome.

\section{Keywords: Angiogenesis, endometrial, fertility, profile, prognostic, arrays.}

\section{Introduction}

Usually deficiency in reproductive system is known as a disease called infertility, and has a negative concept for the vast majority of people. Infertility is a common condition in our days affecting about 10 to 15 percent of reproductive-aged couples [1-4]. It is defined as the failure to achieve a successful pregnancy after 12 months or more of regular and unprotected intercourses [5]. Although the prevalence of infertility is believed to have remained relatively stable during the past 40 years, the demand for infertility evaluation and treatment has increased [6]. Infertility may be caused by male or female factors or both of them. Usually, after 24 months with appropriate treatment $5-10 \%$ of couples achieve pregnancy. Sometimes no specific reason can be found for the patients and the treatment has no successful result. Fortunately, recent advances in assisted reproduction techniques (ART) have provided effective tools for diagnosis and treatment of infertile couples. ART has been used for more than 20 years, reporting an increasing number of cycles treated and an increasing pregnancy rate [7].

Although a number of genetic, immunologic, infection, endocrine and other factors affect fertility, identifying the exact cause of infertility is very important. A large number of independent factors seem to be associated with the success outcome of ART. The crucial role of implantation as a major factor of ART failure has been highlighted in many studies. Synchronization of the availability of good quality oocytes and adequate endometrial maturation are very important for successful implantation [8]. Due to the fact that endometrial maturation varies considerably in each patient, an adequate endometrial

\section{Sofia Paraskevi \\ Trachana ${ }^{1}$,} Eleftherios Pilalis², Depy Mavrogianni ${ }^{1}$, Georgios Patrikios ${ }^{1}$, Manousos Makridakis ${ }^{3}$, Aristotelis Chatziioannou ${ }^{2}$, Peter Drakakis ${ }^{1}$ and Dimitrios Loutradis ${ }^{1}$

${ }^{1}$ First Department of Obstetrics and Gynecology, Medical School, National and Kapodistrian University of Athens, Alexandra General Hospital, Athens, Greece

${ }^{2}$ Enios Applications P.C., Al. Pantou 25, 17671 Kallithea, Greece

${ }^{3}$ Biotechnology Division, Biomedical Research Foundation, Academy of Athens (BRFAA), Athens, Greece

*Author for correspondence:

sp.voula@yahoo.com 
maturation and improved uterine receptivity seem to be the reason for improved pregnancy rates [9]. Characteristics of endometrial tissue such as thickness, volume, blood flow and vessel's architecture, have been associated with its receptivity [10], while other studies support the role of oxytocin receptors in the quality of endometrium, due to the potential interaction of oxytocin receptors with the hormones included in the ovulation induction regiments [11].

Several clinical studies suggest the importance of implantation in a narrow window of uterine receptivity, between 6 and 8 days after ovulation. This brief and precise period, called "implantation window", lasts less than $48 \mathrm{~h}$ and coincides with the formation of large and smooth projections, called "pinopodes", on the apical membranes of the endometrial epithelial cells [12]. Fully developed pinopodes existed for 1 day only which may correspond to the short period of optimal endometrial receptivity, and may suggest the optimal date for successful embryo transfer in ART patients [13]. Finally, other studies have mentioned the role of endometrial secretion cytokines in IVF (in vitro fertilization). Factors, such as tumor necrosis (TNF-a), interleukins (IL-1 $\beta$, IL-6, IL-4), interferon (IFN- $\gamma$ ) and monocyte chemoattractant protein (MCP) in high concentration, are associated with recurrent implantation failure $[14,15]$.

In recent years many studies have focused on the research of new prognostic and predictive factors for the effectiveness of ART. The major role of angiogenesis in embryo implantation and thus, probably in the maintenance of gestation, is under consideration. Implantation and development of a human embryo requires an increased level of angiogenesis. Various growth factors have been associated with placental angiogenesis and embryonic development. Angiogenic factors like Endothelin, Angiogenin, VEGF, and others, have been associated with success outcomes of ART [16].

The aim of the present study was to detect the expression of 55 angiogenic factors in the endometrial tissue of women who underwent ovarian stimulation for ART. We attempted to identify an "angiogenic profile" based on 7 out of 55 angiogenic factors which seems to be associated with success outcomes of ART.

\section{Methods \\ - Patients}

Eight (8) women undergoing ovarian stimulation for Assisted Reproduction Techniques, participated in this observational, single-institution study. All participants met the criteria mentioned in (TABLE 1). Endometrial tissue was prospectively collected but retrospectively analyzed. All patients were treated at the 1st Dept of Obstetrics and Gynecology - Subunit of Reproductive Endocrinology and Infertility (University of Athens, Alexandra General Hospital, Athens, Greece). The ovarian induction protocols, was as in present studies described $[8,9]$.

The study protocol had met appropriate Institutional Review Board approval ( $1^{\text {st }}$ Department of Obstetrics and Gynecology, Alexandra General Hospital, Athens, Greece) and written informed Rconsent was given by all subjects for the collection and study of the endometrial tissue. The study was conducted according to the principles expressed in the declaration of Helsinki.

\section{- Endometrial tissue collection}

Patients' endometrial tissue was collected with the technique of "pipelle biopsy" on the day of oocyte retrieval. All patients previously underwent ovarian stimulation, while all attempts with natural cycle were excluded.

\section{- Protein extraction from tissue}

According to the protocol [17], each tissue was stored and cooled successively to $-20^{\circ} \mathrm{C}$ for 1-2 hours and then transferred to $-80^{\circ} \mathrm{C}$ where it remained until it was to be used. The frozen tissue was first weighed, diced into pieces and further homogenized with mechanical bleder. After being thawed in RIPA buffer ( $3 \mathrm{ml}$ of precold RIPA buffer per gram of tissue), containing Protease Inhibitor and Phosphatase Inhibitor it was incubated on ice for 30 minutes. Finally, it was transferred to microcentrifuge tubes and was submitted in consecutive centrifugations ( 2 times, in $10000 \mathrm{~g}$ and $4{ }^{\circ} \mathrm{C}$, for $10 \mathrm{~min}$ each time) to obtain the product for analysis.

\section{Array based detection of} angiogenic factors

The Proteome Profiler ${ }^{\mathrm{TM}}$ Human Angiogenesis Array Kit, (RnD Systems, USA 


\begin{tabular}{|c|c|c|c|c|c|c|c|c|}
\hline & & & patients & & & & & \\
\hline Protein Name & u781 & u782 & u783 & u784 & u925 & u926 & u927 & u928 \\
\hline Positive Control & 390.42 & 396.00 & 398.85 & 350.06 & 357.30 & 383.93 & 363.27 & 348.36 \\
\hline Activin A & 0.38 & 0.27 & 0.72 & 1.15 & -0.15 & 0.88 & 0.01 & 0.34 \\
\hline ADAMTS-1 & 1.11 & 0.73 & 9.54 & 2.85 & 20.90 & 6.02 & 0.86 & 0.71 \\
\hline Angiogenin & 195.93 & 345.58 & 428.90 & 412.43 & 395.53 & 463.00 & 361.27 & 329.17 \\
\hline Angiopoietin - 1 & 6.44 & 2.14 & 31.91 & 29.84 & 78.24 & 87.75 & 2.75 & 1.05 \\
\hline Angiopoietin - 2 & 110.33 & 10.70 & 201.64 & 125.56 & 280.20 & 233.71 & 5.17 & 3.36 \\
\hline Angiostatin / Plasminogen & 5.56 & 1.68 & 20.24 & 4.67 & 89.17 & 79.18 & 0.95 & 1.71 \\
\hline Amphiregulin & 1.40 & 0.52 & -3.10 & 2.11 & 12.72 & 8.61 & 0.01 & 0.22 \\
\hline Artemin & 5.00 & 1.30 & 10.57 & 1.54 & 50.32 & 35.95 & 0.31 & 0.52 \\
\hline Positive Control & 388.75 & 355.04 & 333.42 & 350.78 & 384.56 & 345.30 & 350.76 & 350.73 \\
\hline Coagulation Factor III & 217.88 & 252.24 & 305.60 & 184.30 & 411.47 & 427.85 & 223.51 & 174.89 \\
\hline CXCL16 & 2.06 & 1.43 & 44.90 & 21.16 & 65.29 & 81.12 & 1.17 & 0.91 \\
\hline DPPIV & 133.97 & 75.26 & 347.52 & 232.16 & 242.98 & 382.63 & 54.66 & 95.38 \\
\hline EGF & 1.47 & 1.04 & 13.75 & 4.84 & 26.45 & 12.68 & 0.95 & 0.54 \\
\hline EG - VEGF & 2.94 & 2.65 & 227.32 & 6.78 & 144.15 & 42.51 & 1.84 & 1.03 \\
\hline Endoglin & 4.63 & 2.02 & 235.90 & 63.94 & 213.57 & 296.37 & 2.14 & 3.61 \\
\hline Endostatin / Collagen XVIII & 111.73 & 84.66 & 228.70 & 110.41 & 272.49 & 266.86 & 50.00 & 36.91 \\
\hline Endothelin - 1 & 267.70 & 160.66 & 209.75 & 297.27 & 316.48 & 360.23 & 104.74 & 75.91 \\
\hline FGF acidic & 4.91 & 1.90 & 22.86 & 41.73 & 231.87 & 381.12 & 1.71 & 0.76 \\
\hline FGF basic & 5.14 & 36.59 & 263.76 & 259.01 & 245.16 & 193.81 & 35.70 & 283.39 \\
\hline FGF - 4 & 1.18 & 0.99 & 1.97 & 1.77 & 32.84 & 2.33 & 0.34 & 0.44 \\
\hline FGF - 7 & 1.60 & 0.81 & 53.25 & 32.00 & 83.00 & 2.71 & 0.92 & 1.40 \\
\hline GDNF & 1.38 & 0.77 & 4.02 & 1.37 & 50.74 & 14.74 & 0.67 & 1.09 \\
\hline GM - CSF & 1.20 & 1.07 & 13.66 & 5.15 & 42.34 & 23.24 & 1.26 & 0.68 \\
\hline $\mathrm{HB}$ - EGF & 4.44 & 2.18 & 75.52 & 14.09 & 73.50 & 93.03 & 2.04 & 0.68 \\
\hline HGF & 2.37 & 2.72 & 204.44 & 137.81 & 78.89 & 143.75 & 5.01 & 3.68 \\
\hline IGFBP - 1 & 24.88 & 2.60 & 150.01 & 68.86 & 173.70 & 140.88 & 1.88 & 1.30 \\
\hline IGFBP - 2 & 12.48 & 85.36 & 336.73 & 299.70 & 346.76 & 398.40 & 63.50 & 119.15 \\
\hline IGFBP - 3 & 54.20 & 27.50 & 202.47 & 218.86 & 315.16 & 423.10 & 45.03 & 8.43 \\
\hline IL $-1 \beta$ & 2.20 & 0.39 & 3.91 & 2.70 & 24.41 & 26.86 & 0.56 & 0.50 \\
\hline IL - 8 & 1.22 & 1.53 & 267.19 & 293.65 & 15.66 & 254.26 & 1.72 & 2.77 \\
\hline $\operatorname{LAP}(\mathrm{TGF}-\beta 1)$ & 3.92 & 1.51 & 38.18 & 29.53 & 63.98 & 22.81 & 1.70 & 1.68 \\
\hline Leptin & 1.22 & 0.76 & 3.74 & 2.90 & 33.88 & 3.35 & 0.35 & 0.49 \\
\hline MCP - 1 & 2.07 & 1.24 & 81.37 & 272.19 & 51.53 & 92.87 & 0.69 & 2.03 \\
\hline MIP - 1a & 0.17 & 0.54 & 1.93 & 1.04 & 27.46 & 9.21 & 0.50 & 0.40 \\
\hline MMP-8 & 16.03 & 78.81 & 306.56 & 208.75 & 185.25 & 349.30 & 82.71 & 34.92 \\
\hline MMP-9 & 16.38 & 46.29 & 306.10 & 202.63 & 188.65 & 419.16 & 71.07 & 0.00 \\
\hline NRG1 - $\beta 1$ & 2.58 & 2.40 & 84.07 & 51.15 & 50.55 & 80.41 & 2.08 & 0.63 \\
\hline Pentraxin 3 (PTX3) & 1.83 & 0.56 & 49.21 & 13.98 & 42.42 & 59.53 & 0.52 & 0.60 \\
\hline PD-ECGF & 37.81 & 3.83 & 111.64 & 20.01 & 160.23 & 176.90 & 2.20 & 2.97 \\
\hline PDGF-AA & 2.28 & 0.78 & -2.63 & 6.29 & 38.63 & 60.50 & 1.69 & 1.03 \\
\hline PDGF-AB/PDGF-BB & 1.10 & 0.41 & 4.96 & 11.16 & 19.46 & 12.58 & 0.80 & 1.20 \\
\hline Persephin & 54.88 & 4.14 & 36.78 & 14.09 & 125.63 & 141.21 & 1.88 & 1.58 \\
\hline Platelet Factor 4 (PF4) & 275.98 & 239.73 & 359.32 & 346.85 & 365.87 & 354.10 & 220.00 & 233.78 \\
\hline PIGF & 7.60 & 3.20 & 35.06 & 50.13 & 112.77 & 91.29 & 3.22 & 3.14 \\
\hline Prolactin & 2.79 & 0.80 & 40.44 & 12.67 & 69.27 & 34.59 & 0.19 & 0.44 \\
\hline Serpin B5 & 0.39 & 0.86 & 1.31 & 1.79 & 26.00 & 4.40 & 0.42 & 0.47 \\
\hline serpin E1 & 6.39 & 28.44 & 299.88 & 242.24 & 180.69 & 81.50 & 28.42 & 85.66 \\
\hline Serpin F1 & 202.90 & 168.52 & 223.58 & 138.63 & 299.23 & 402.53 & 136.49 & 0.09 \\
\hline TIMP - 1 & 98.72 & 287.49 & 462.55 & 468.91 & 348.67 & 504.09 & 297.04 & 296.67 \\
\hline TIMP- 4 & 2.32 & 45.53 & 19.04 & 10.91 & 56.78 & 55.18 & 1.39 & 0.71 \\
\hline Thrombospondin - 1 & 2.57 & 0.99 & 27.24 & 28.06 & 66.78 & 136.47 & 0.40 & 0.32 \\
\hline Thrombospondin - 2 & 0.94 & 0.24 & 0.67 & 1.06 & 11.80 & 7.02 & 0.24 & 0.29 \\
\hline uPA & 73.29 & 191.27 & 324.01 & 403.37 & 271.84 & 389.57 & 303.73 & 251.05 \\
\hline
\end{tabular}




\begin{tabular}{|l|l|l|l|l|l|l|l|l|}
\hline Vasohibin & 2.43 & 0.63 & 0.64 & 0.79 & 27.53 & 12.53 & 0.49 & 0.45 \\
\hline VEGF & 19.37 & 5.92 & 107.70 & 100.39 & 98.80 & 96.84 & 4.55 & 2.79 \\
\hline VEGF - C & 0.78 & 0.28 & 0.07 & 0.53 & 16.78 & 1.71 & 0.01 & 0.14 \\
\hline Positive Control & 288.81 & 316.94 & 335.71 & 367.14 & 326.12 & 338.75 & 353.96 & 336.67 \\
\hline
\end{tabular}

\section{TABLE 1: Inclusion criteria for the participating patients.}

1 Age $\leq 45$ years old.

2 Written informed consent should be signed.

3 Normal hormonal profile.

4 The patients should not have any genetic disorders.

5 Factors such as the protocol to be used for ovarian stimulation, and past attempts with ART, are not affect the participation of the patients in the study.

Catalog Number: ARRY 007) [18], was applied to screen for the presence of 55 soluble angiogenesis related factors present in the patients' endometrial tissue according to the manufacturer's instructions.

Briefly, fifty - five antibodies specific to relevant angiogenic factors (shown in TABLE 2) are attached onto a cellulose membrane fixed in duplicate.

One (1) $\mathrm{ml}$ of the sample is incubated with $500 \mu \mathrm{l}$ of a relevant buffer and 15 microliters of a mixture of biotynilated antibodies for 1 hour. A special plate is provided where the kit's antibody coated membrane is also incubated for 1 hour with a blocking buffer in order to avoid subsequent non-specific binding of antibodies to proteins of interest. The blocking buffer is then removed and the membrane was incubated with the sample-antibody mixture (prepared in previous step) for 16 hours at $4{ }^{\circ} \mathrm{C}$. The following day, the mixture of supernatantantibody-buffer is drained off the membrane which is subsequently washed 3 times with Wash Buffer for 10 minutes at a time and then the membrane is incubated with streptavidinHRP for 30 minutes.

Another wash is performed and finally the membrane is incubated with a chemiluminescent detection reagent. Protein targets were detected by enhanced chemiluminescence.

This way the proteins associated with angiogenesis are detected, present in endometrial tissue and reflect an angiogenic profile for each patient (FIGURE 1).

Films were scanned at a GS-800 imaging densitometer (Bio Rad) in transmission mode and the images were analyzed using the Quantity One 4.4.1 Software package (Bio Rad).
TABLE 2: The fifty five angiogenesis related factors used.

Protein Name

\begin{tabular}{|l|l|l|}
\hline Activin A & FGF-7 & PDGF-AB/PDGF-BB \\
\hline
\end{tabular}

\begin{tabular}{l|l|l}
\hline ADAMTS-1 & GDNF & Persephin
\end{tabular}

\begin{tabular}{l|l|l}
\hline Angiogenin & GM-CSF & Platelet Factor 4 (PF4)
\end{tabular}

Angiopoietin-1 HB-EGF PIGF

\begin{tabular}{l|l|l} 
Angiopoietin-2 & HGF & Prolactin \\
\hline Angiostatin/
\end{tabular}

\begin{tabular}{l|l|l} 
Angiostatin/ IGFBP-1 Serpin B5 &
\end{tabular}

\begin{tabular}{l|l|l} 
Plasminogen & IGFB-1 & \\
\hline Amphiregulin & IGFBP-2 & Serpin E1 \\
\hline
\end{tabular}

\begin{tabular}{l|l|l}
\hline Artemin & IGFBP-3 & Serpin F1 \\
\hline
\end{tabular}

Artemin $-1 \beta$ Serpin F1

\begin{tabular}{|l|l|l} 
FGF-4 IL-1 $\beta$ & TIMP-1 \\
\hline Coagulation Factor & &
\end{tabular}

\begin{tabular}{l|l|l} 
III & IL-8 & TIMP-4
\end{tabular}

\begin{tabular}{l|l|l} 
CXCL16 & LAP & Thrombospondin-1 \\
\hline
\end{tabular}

\begin{tabular}{l|l|l}
\hline DPPIV & Leptin & Thrombospondin-2
\end{tabular}

EGF $\quad$ MCP-1 UPA

\begin{tabular}{l|l|l} 
EG-VEGF & MIP-1a & Vasohibin
\end{tabular}

\begin{tabular}{l|l|l} 
Endoglin & MMP-8 & VEGF
\end{tabular}

\begin{tabular}{l|l|l} 
Endostatin/ & MMP-9 & VEGF $-C$ \\
Collagen XVIII
\end{tabular}

\begin{tabular}{l|l|l}
\hline Endothelin-1 & NRG1- $\beta 1$ & PDGF-AA
\end{tabular}

\begin{tabular}{l|l} 
FGF acidic & Pentraxi \\
\hline (PTX3)
\end{tabular}

\begin{tabular}{l|l} 
FGF basic & PD-ECGF
\end{tabular}

- Principal component analysis (PCA) and statistical analysis

For the analysis of array's results, PCA was performed. PCA is a statistical procedure that uses an orthogonal transformation to convert a set of observations of possibly correlated variables into a set of values of linearly uncorrelated variables called principal components. The first principal component has the largest possible variance (that is, accounts for as much of the variability in the data as possible). For the statistical analysis, the non-parametric MannWhitney and Fisher's exact tests were used. 


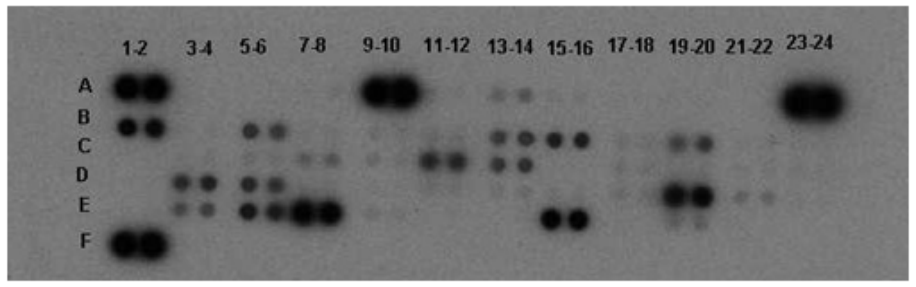

\begin{tabular}{|c|c|c|c|c|c|c|c|c|c|c|c|c|}
\hline & $1-2$ & $3-4$ & $5-6$ & $7-8$ & 9-10 & $11-12$ & 13-14 & $15-16$ & $17-18$ & $19-20$ & $21-22$ & $23-24$ \\
\hline A & pos & & ${ }_{A}^{A c t i v i n}$ & ADAMTS-1 & Angiogenin & Angiopoietin-1 & Angiopoietin-2 & 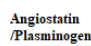 & Amphiregulin & Artemin & & pos \\
\hline B & $\begin{array}{l}\text { Coagulation } \\
\text { Factor III }\end{array}$ & CxcL16 & DPPN & EGF & EG-VIGF & Endoglin & $\begin{array}{l}\text { Endostatin / } \\
\text { Collagen XXIII }\end{array}$ & Endothelin-1 & FGF-acidic & 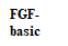 & FGF-4 & FGE-7 \\
\hline C & GDNF & GM-CSF & $\begin{array}{l}\text { HB- } \\
\text { EGF }\end{array}$ & HGF & IGFBP-1 & IGFBP-2 & IGFBP-3 & 世-1 $1 \beta$ & $\mathrm{L}-\mathrm{s}$ & $\begin{array}{l}\text { LAP } \\
\text { (TGF-B1) }\end{array}$ & Leptin & MCP-1 \\
\hline D & MIIP. $\mathrm{I}^{e}$ & MMP-s & MMPP.9 & NRG1-p1 & PTX3 & PD-ECGF & PDGF-AA & $\begin{array}{l}\text { PDGFABA } \\
\text { PDGF-BB }\end{array}$ & Persephin & PF4 & PIGF & Prolactin \\
\hline E & Serpin B5 & Serpin El & $\begin{array}{l}\text { Seppin } \\
\mathrm{F} 1\end{array}$ & TMPP.1 & TIMP-4 & $\begin{array}{l}\text { Thrombo- } \\
\text { spondin } 1\end{array}$ & $\begin{array}{l}\text { Thrombo- } \\
\text { spondin } 2\end{array}$ & uPA & Vasohibin & IEGF & $\underset{\mathrm{c}}{\mathrm{IEGF}-}$ & \\
\hline $\mathbf{F}$ & pos & & & & & & & & & & & NEG \\
\hline
\end{tabular}

FIGURE 1. Angiogenic profile using Protein Arrays.

Demonstration of the angiogenic profile determined in the endometrial tissue of a participant patient (u927), using the Proteome Profiler Angiogenesis Array kit. Each spot corresponds to an angiogenic factor shown in the Table below.

\section{Results}

\section{- Patients}

From February 2014 to February 2015 samples of endometrial tissue from 8 patients who underwent ovarian stimulation, were obtained. Their characteristics are shown in Table 3. Six out of 8 women had female infertility factor while in 2 cases the factor was male. All patients received treatment for ovarian stimulation. No ovarian hyperstimulation was observed and no cycle was canceled for any reason.

\section{- Results of Principal component analysis (PCA)}

PCA was performed ( $\mathrm{R}$ package FactoMineR,) [19] in order to evaluate the contribution of each sample to the variance of the dataset, as well as to inspect the correlation among samples. FIGURE $\mathbf{2}$ shows the projection of samples to the first two principal components, which together account for $86.79 \%$ of the total variance. From the dataset of the 55 angiogenic factors, seven factors seem to be clearly distinguished from the others, due to their higher expression and their optimal combination (TABLE 4). It is very important to mention that this method is mainly based on the results derived from the combination of the factors. For example, other factors have high expression too, but they are not included in the

\begin{tabular}{|l|l|}
\hline TABLE 3: Baseline characteristics of patients. \\
\hline Characteristics & N (\%) \\
\hline Age (median, range) & $35,5(29-43)$ \\
\hline Years of infertility (median, age) & $3,875(2-8)$ \\
\hline $\begin{array}{l}\text { Number of previous attempts } \\
\text { (median, range) }\end{array}$ & $2,125(2-7)$ \\
\hline Hormonological profil (median, range) & \\
\hline FSH (IU/L) & $7,3(3,2-13,99)$ \\
\hline LH (IU/L) & $5,54(2,9-12,4)$ \\
\hline E2 (pg/mL) & $39,96(13-63)$ \\
\hline PRL (ng/mL) & $17,3(5,65-$ \\
\hline TSH (mIU/L) & $31,8)$ \\
\hline Protocols & $2,2(1,26-4,27)$ \\
\hline GnRH antagonist & \\
\hline GnRH agonist & $4(50 \%)$ \\
\hline Endometrial thickness on day of \\
oocyte retrieval (median,range) $\mathrm{mm}$ & $4(50 \%)$ \\
\hline Pregnancy & $10,15(7-12)$ \\
\hline Pregnancy & \\
\hline Biochemical pregnancy & $2(25 \%)$ \\
\hline No pregnancy & $1(12,5 \%)$ \\
\hline Extrauterine pregnancy & $5(62,5 \%)$ \\
\hline & 0 \\
\hline
\end{tabular}

subset of the seven since their combination with the other factors is not optimal for separating the patients into groups.

All protein array data for the 55 factors are included in Supplementary TABLE 1. Based on the expression and the optimal combination of the 7 dominant factors, the samples form two groups with correlated expressions. This was confirmed by the image of FIGURE 3 


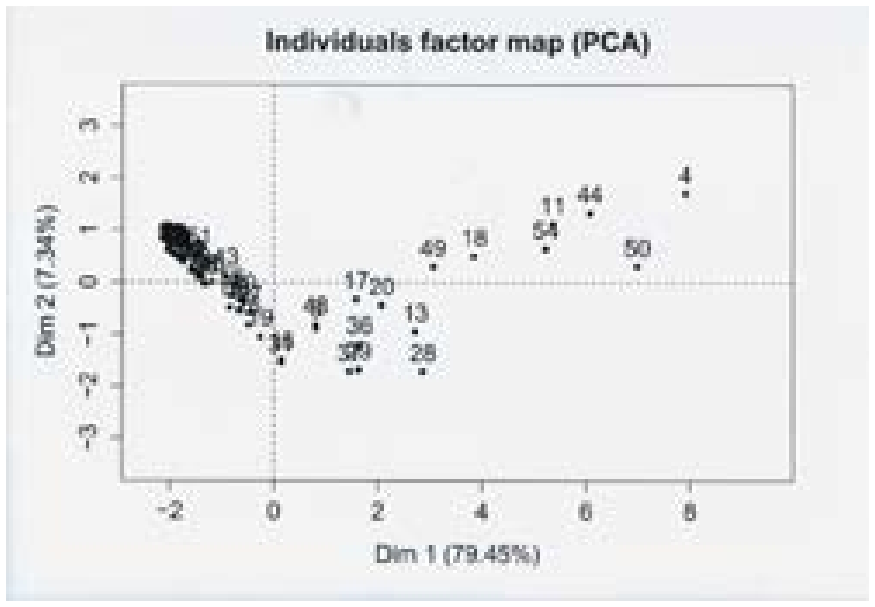

FIGURE 2: Principal component analysis.

Figure $\mathbf{2}$ depicts the expression of the $\mathbf{5 5}$ angiogenic factors and their projection to the first two principal components. Seven factors (number 4, 50, 44,11,54,18 and 49) (TABLE 4) seems to be distinguished from the others due to their higher expression.

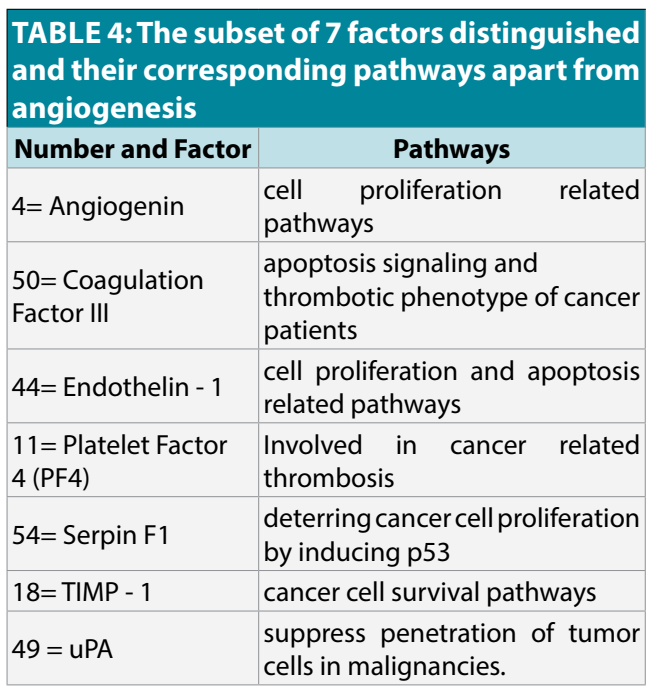

(euclidian distance, $\mathrm{R}$ package gplots) which shows that the dataset can be separated in two clusters (Cluster 1: u927, u782, u781, u928 and Cluster 2: u925, u926, u783, u784).

As it shows in FIGURE 3, the 8 patients are clearly separated into 2 subsets. The first subset includes patients u927, u782, u781, and u928. In this group one biochemical pregnancy was achieved in patient $\mathrm{u} 782$. The second cluster includes patients u925, u784, u926 and u783. In this subset, there were two pregnancies in patients u926 and u783.

The differences in the expression levels of the 55 factors among the patients are depicted in the HeatMap of FIGURE 4. For each patient, the expression level of each factor was compared to the median expression among all 8 patients.

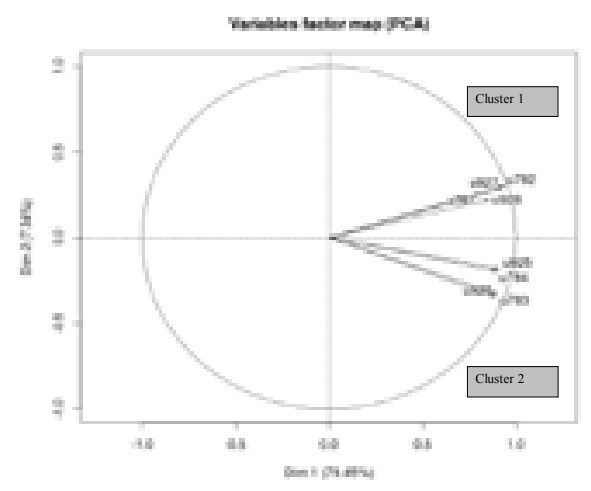

FIGURE 3: Separation of the 8 samples in two groups.

The separation of the 8 samples in two groups was based on the expression of the 7 dominant factors. Patients u927, u782, u781, and $\mathbf{4} 928$ are included in the first group, among them one biochemical pregnancy was achieved in patient $\mathbf{u 7 8 2}$. The second cluster includes Patients u925, u784, u926 and u783 are included in the second cluster in which two pregnancies in patients' u926 and u783 were achieved.

The visualization of the separation of the two groups is almost ideal since the two clusters are clearly separated and the highest expression level of the factors in the second cluster is obvious.

\section{Statistical Analysis}

The non-parametric Mann - Whitney U test, was used in order to estimate if there is any significant difference in angiogenic factors both for all 55 factors (TABLE 5a-placed at the end of the document) and for the 7 dominant factors (TABLE $5 \mathbf{b}$ - placed at the end of the 


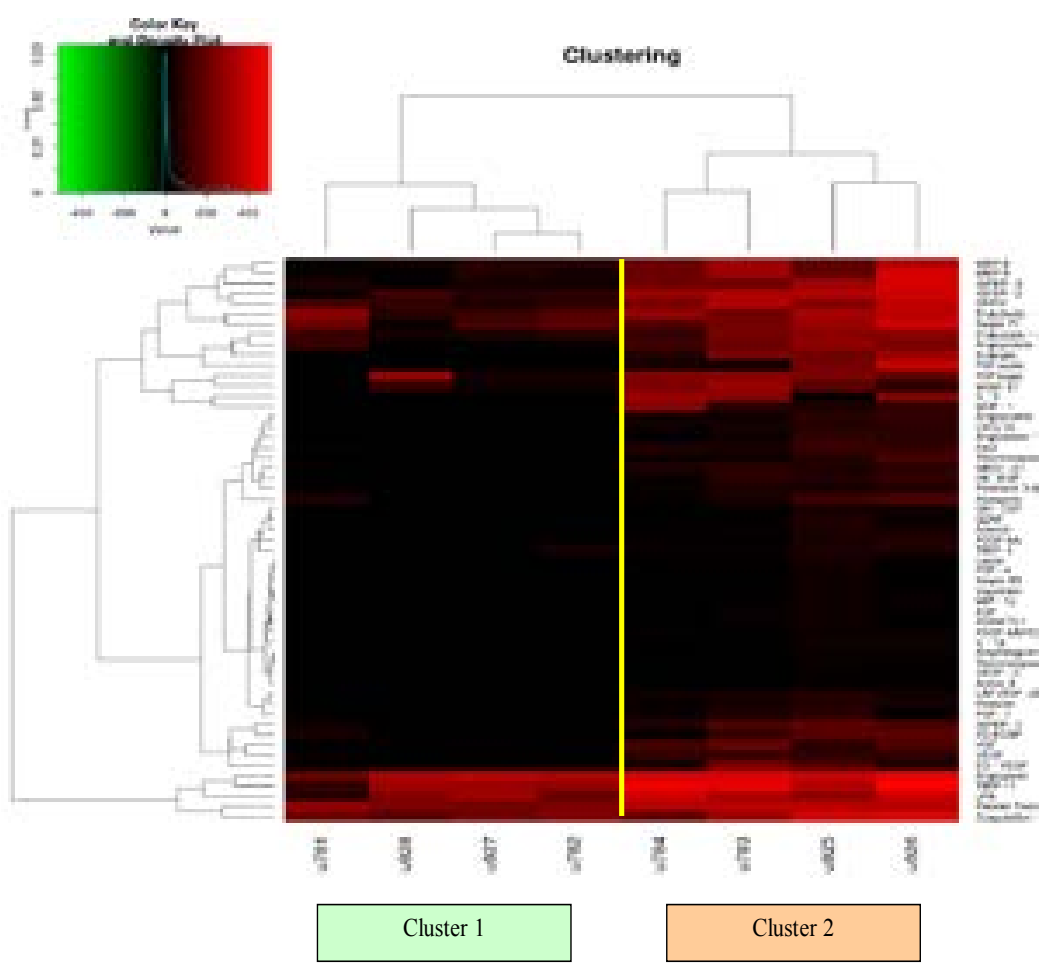

FIGURE 4: HeatMap of expression level of the 55 angiogenic factors, including the dominant 7. Relative expression levels of the $\mathbf{5 5}$ angiogenic factors. Expression values are displayed according to the colour scale, in which red expression above median expression and green represents below median expression. The two clusters are clearly separated. In the second cluster the expression level is obviously higher than in the first cluster. Intrauterine pregnancy achieved in patients' u926 and u783, who have very high expression level.

\begin{tabular}{|c|c|c|c|c|c|c|}
\hline & pregnancy & $\mathbf{N}$ & Mean & Std. Deviation & Std. Error Mean & p-value \\
\hline \multirow{2}{*}{ Activin A } & No & 5 & 0,26 & 0,34 & 0,15 & 0,180 \\
\hline & yes & 3 & 0,77 & 0,45 & 0,26 & \\
\hline \multirow{2}{*}{ ADAMTS-1 } & No & 5 & 6,62 & 8,82 & 3,94 & 0,881 \\
\hline & Yes & 3 & 3,20 & 2,66 & 1,54 & \\
\hline \multirow{2}{*}{ Angiogenin } & No & 5 & 342,16 & 89,85 & 40,18 & 0,297 \\
\hline & Yes & 3 & 407,00 & 58,90 & 34,00 & \\
\hline \multirow{2}{*}{ Angiopoietin - 1} & No & 5 & 24,08 & 32,75 & 14,65 & 0,655 \\
\hline & Yes & 3 & 39,91 & 43,68 & 25,22 & \\
\hline \multirow{2}{*}{ Angiopoietin - 2} & No & 5 & 120,14 & 121,67 & 54,41 & 0,655 \\
\hline & Yes & 3 & 123,32 & 111,52 & 64,39 & \\
\hline \multirow{2}{*}{$\begin{array}{l}\text { Angiostatin / } \\
\text { Plasminogen }\end{array}$} & No & 5 & 23,53 & 37,51 & 16,78 & 0,881 \\
\hline & Yes & 3 & 28,51 & 43,91 & 25,35 & \\
\hline \multirow{2}{*}{ Amphiregulin } & No & 5 & 2,25 & 6,08 & 2,72 & 0,297 \\
\hline & Yes & 3 & 3,75 & 4,29 & 2,47 & \\
\hline \multirow{2}{*}{ Artemin } & No & 5 & 13,34 & 21,09 & 9,43 & 0,881 \\
\hline & Yes & 3 & 12,93 & 19,94 & 11,51 & \\
\hline \multirow{2}{*}{$\begin{array}{l}\text { Coagulation Factor } \\
\text { III }\end{array}$} & No & 5 & 266,67 & 93,74 & 41,92 & 0,655 \\
\hline & Yes & 3 & 288,13 & 125,68 & 72,56 & \\
\hline \multirow{2}{*}{ CXCL16 } & No & 5 & 22,87 & 30,29 & 13,55 & 0,456 \\
\hline & Yes & 3 & 34,57 & 41,50 & 23,96 & \\
\hline
\end{tabular}




\begin{tabular}{|c|c|c|c|c|c|c|}
\hline & No & 5 & 174,90 & 119,26 & 53,33 & 0,655 \\
\hline DPPIV & Yes & 3 & 230,02 & 153,70 & 88,74 & \\
\hline \multirow{2}{*}{ EGF } & No & 5 & 8,63 & 11,40 & 5,10 & 0,881 \\
\hline & Yes & 3 & 6,19 & 5,94 & 3,43 & \\
\hline \multirow{2}{*}{ EG - VEGF } & No & 5 & 75,46 & 104,88 & 46,90 & 0,881 \\
\hline & Yes & 3 & 17,31 & 21,92 & 12,65 & \\
\hline \multirow{2}{*}{ Endoglin } & No & 5 & 91,97 & 121,46 & 54,32 & 0,881 \\
\hline & Yes & 3 & 120,78 & 155,19 & 89,60 & \\
\hline \multirow{2}{*}{$\begin{array}{l}\text { Endostatin / } \\
\text { Collagen XVIII }\end{array}$} & No & 5 & 139,97 & 106,00 & 47,41 & 0,881 \\
\hline & Yes & 3 & 153,98 & 98,60 & 56,93 & \\
\hline \multirow{2}{*}{ Endothelin - 1} & No & 5 & 194,92 & 103,19 & 46,15 & 0,297 \\
\hline & Yes & 3 & 272,72 & 102,02 & 58,90 & \\
\hline \multirow{2}{*}{ FGF acidic } & No & 5 & 52,42 & 100,71 & 45,04 & 0,297 \\
\hline & Yes & 3 & 141,58 & 208,40 & 120,32 & \\
\hline \multirow{2}{*}{ FGF basic } & No & 5 & 166,63 & 134,59 & 60,19 & 0,881 \\
\hline & Yes & 3 & 163,14 & 114,34 & 66,01 & \\
\hline \multirow{2}{*}{ FGF - 4} & No & 5 & 7,35 & 14,26 & 6,38 & 0,655 \\
\hline & Yes & 3 & 1,70 & 0,67 & 0,39 & \\
\hline \multirow{2}{*}{ FGF - 7} & No & 5 & 28,03 & 38,08 & 17,03 & 0,655 \\
\hline & Yes & 3 & 11,84 & 17,48 & 10,09 & \\
\hline \multirow{2}{*}{ GDNF } & No & 5 & 11,58 & 21,93 & 9,81 & 0,881 \\
\hline & Yes & 3 & 5,63 & 7,90 & 4,56 & \\
\hline \multirow{2}{*}{ GM - CSF } & No & 5 & 11,83 & 17,91 & 8,01 & 0,881 \\
\hline & Yes & 3 & 9,82 & 11,80 & 6,81 & \\
\hline \multirow{2}{*}{$\mathrm{HB}-\mathrm{EGF}$} & No & 5 & 31,24 & 39,53 & 17,68 & 0,456 \\
\hline & Yes & 3 & 36,43 & 49,37 & 28,51 & \\
\hline \multirow{2}{*}{ HGF } & No & 5 & 58,88 & 87,65 & 39,20 & 0,655 \\
\hline & Yes & 3 & 94,76 & 79,76 & 46,05 & \\
\hline \multirow{2}{*}{ IGFBP - 1} & No & 5 & 70,35 & 84,48 & 37,78 & 0,881 \\
\hline & Yes & 3 & 70,78 & 69,16 & 39,93 & \\
\hline \multirow{2}{*}{ IGFBP - 2} & No & 5 & 175,72 & 156,22 & 69,86 & 0,456 \\
\hline & Yes & 3 & 261,15 & 160,04 & 92,40 & \\
\hline \multirow{2}{*}{ IGFBP - 3} & No & 5 & 125,06 & 129,58 & 57,95 & 0,456 \\
\hline & Yes & 3 & 223,15 & 197,83 & 114,22 & \\
\hline \multirow{2}{*}{ IL $-1 \beta$} & No & 5 & 6,32 & 10,21 & 4,57 & 0,881 \\
\hline & Yes & 3 & 9,98 & 14,66 & 8,46 & \\
\hline \multirow{2}{*}{ IL - 8} & No & 5 & 57,71 & 117,25 & 52,44 & 0,456 \\
\hline & Yes & 3 & 183,15 & 158,51 & 91,52 & \\
\hline \multirow{2}{*}{ LAP (TGF - $\beta 1)$} & No & 5 & 21,89 & 28,18 & 12,60 & 0,655 \\
\hline & Yes & 3 & 17,95 & 14,63 & 8,45 & \\
\hline Ientin & No & 5 & 7,94 & 14,57 & 6,51 & 0,881 \\
\hline Leptin & Yes & 3 & 2,34 & 1,38 & 0,80 & \\
\hline MCP - 1 & No & 5 & 27,54 & 37,06 & 16,57 & 0,297 \\
\hline IVICP -1 & Yes & 3 & 122,10 & 137,82 & 79,57 & \\
\hline MIP - 10 & No & 5 & 6,09 & 11,97 & 5,35 & 0,456 \\
\hline IVIIF - Ia & Yes & 3 & 3,60 & 4,87 & 2,81 & \\
\hline MMP_8 & No & 5 & 125,09 & 120,80 & 54,02 & 0,297 \\
\hline IVIIVIT-O & Yes & 3 & 212,29 & 135,28 & 78,10 & \\
\hline MMP_q & No & 5 & 116,44 & 129,24 & 57,80 & 0,297 \\
\hline Tivivir - & Yes & 3 & 222,69 & 187,24 & 108,10 & \\
\hline NRG1 - $\beta 1$ & No & 5 & 27,98 & 37,81 & 16,91 & 0,456 \\
\hline IVI & Yes & 3 & 44,65 & 39,41 & 22,75 & \\
\hline & No & 5 & 18,92 & 24,68 & 11,04 & 0,655 \\
\hline
\end{tabular}




\begin{tabular}{|c|c|c|c|c|c|c|}
\hline Pentraxin 3 (PTX3) & Yes & 3 & 24,69 & 30,91 & 17,85 & \\
\hline \multirow{2}{*}{ PD-ECGF } & No & 5 & 62,97 & 70,27 & 31,43 & 0,655 \\
\hline & Yes & 3 & 66,91 & 95,59 & 55,19 & \\
\hline \multirow{2}{*}{ PDGF-AA } & No & 5 & 8,20 & 17,12 & 7,66 & 0,456 \\
\hline & Yes & 3 & 22,52 & 33,00 & 19,05 & \\
\hline \multirow{2}{*}{ PDGF-AB/PDGF-BB } & No & 5 & 5,50 & 7,99 & 3,57 & 0,881 \\
\hline & Yes & 3 & 8,05 & 6,65 & 3,84 & \\
\hline \multirow{2}{*}{ Persephin } & No & 5 & 44,15 & 51,01 & 22,81 & 0,655 \\
\hline & Yes & 3 & 53,15 & 76,43 & 44,13 & \\
\hline \multirow{2}{*}{$\begin{array}{c}\text { Platelet Factor } 4 \\
\text { (PF4) }\end{array}$} & No & 5 & 290,99 & 68,58 & 30,67 & 0,881 \\
\hline & Yes & 3 & 313,56 & 64,04 & 36,97 & \\
\hline \multirow{2}{*}{ PIGF } & No & 5 & 32,36 & 46,88 & 20,96 & 0,655 \\
\hline & Yes & 3 & 48,21 & 44,08 & 25,45 & \\
\hline \multirow{2}{*}{ Prolactin } & No & 5 & 22,63 & 31,15 & 13,93 & 0,881 \\
\hline & Yes & 3 & 16,02 & 17,14 & 9,90 & \\
\hline \multirow{2}{*}{ Serpin B5 } & No & 5 & 5,72 & 11,34 & 5,07 & 0,297 \\
\hline & Yes & 3 & 2,35 & 1,84 & 1,06 & \\
\hline \multirow{2}{*}{ serpin E1 } & No & 5 & 120,21 & 120,95 & 54,09 & 0,881 \\
\hline & Yes & 3 & 117,39 & 111,33 & 64,28 & \\
\hline \multirow{2}{*}{ Serpin F1 } & No & 5 & 172,46 & 112,49 & 50,31 & 0,655 \\
\hline & Yes & 3 & 236,56 & 144,51 & 83,43 & \\
\hline \multirow{2}{*}{ TIMP - 1} & No & 5 & 300,73 & 131,65 & 58,87 & 0,297 \\
\hline & Yes & 3 & 420,16 & 116,24 & 67,11 & \\
\hline \multirow{2}{*}{ TIMP- 4} & No & 5 & 16,05 & 24,01 & 10,74 & 0,297 \\
\hline & Yes & 3 & 37,21 & 23,28 & 13,44 & \\
\hline \multirow{2}{*}{$\begin{array}{c}\text { Thrombospondin } \\
-1\end{array}$} & No & 5 & 19,46 & 28,79 & 12,87 & 0,297 \\
\hline & Yes & 3 & 55,17 & 71,69 & 41,39 & \\
\hline \multirow{2}{*}{$\begin{array}{c}\text { Thrombospondin } \\
-2\end{array}$} & No & 5 & 2,79 & 5,05 & 2,26 & 0,764 \\
\hline & Yes & 3 & 2,77 & 3,70 & 2,14 & \\
\hline \multirow{2}{*}{ uPA } & No & 5 & 244,78 & 99,92 & 44,68 & 0,297 \\
\hline & Yes & 3 & 328,07 & 118,67 & 68,52 & \\
\hline \multirow{2}{*}{ Vasohibin } & No & 5 & 6,31 & 11,89 & 5,32 & 0,655 \\
\hline & Yes & 3 & 4,65 & 6,82 & 3,94 & \\
\hline \multirow{2}{*}{ VEGF } & No & 5 & 46,64 & 52,17 & 23,33 & 0,655 \\
\hline & Yes & 3 & 67,72 & 53,55 & 30,92 & \\
\hline \multirow{2}{*}{ VEGF - C } & No & 5 & 3,56 & 7,40 & 3,31 & 0,456 \\
\hline & Yes & 3 & 0,84 & 0,76 & 0,44 & \\
\hline
\end{tabular}

\begin{tabular}{|c|c|c|c|c|c|c|}
\hline Factor & pregnancy & $\mathbf{N}$ & Mean & Std. Deviation & Std. Error Mean & p-value \\
\hline \multirow{2}{*}{ Angiogenin } & no & 5 & 342,16 & 89,85 & 40,18 & 0,297 \\
\hline & yes & 3 & 407,00 & 58,90 & 34,00 & \\
\hline \multirow{2}{*}{ Coagulation Factor III } & no & 5 & 266,67 & 93,74 & 41,92 & 0,655 \\
\hline & yes & 3 & 288,13 & 125,68 & 72,56 & \\
\hline \multirow{2}{*}{ Endothelin - 1} & no & 5 & 194,92 & 103,19 & 46,15 & 0,297 \\
\hline & yes & 3 & 272,72 & 102,02 & 58,90 & \\
\hline \multirow{2}{*}{ Platelet Factor 4 (PF4) } & no & 5 & 290,99 & 68,58 & 30,67 & 0,881 \\
\hline & yes & 3 & 313,56 & 64,04 & 36,97 & \\
\hline \multirow{2}{*}{ Serpin F1 } & no & 5 & 172,46 & 112,49 & 50,31 & 0,655 \\
\hline & yes & 3 & 236,56 & 144,51 & 83,43 & \\
\hline \multirow{2}{*}{ TIMP - 1} & no & 5 & 300,73 & 131,65 & 58,87 & 0,297 \\
\hline & yes & 3 & 420,16 & 116,24 & 67,11 & \\
\hline \multirow{2}{*}{ uPA } & no & 5 & 244,78 & 99,92 & 44,68 & 0,297 \\
\hline & yes & 3 & 328,07 & 118,67 & 68,52 & \\
\hline
\end{tabular}


document), between the patients who achieve pregnancy (including the biochemical one) and the others. The results showed no significant difference between the 2 groups.

\section{Discussion}

In the current study, we investigated the contribution and the importance of a set of 55 angiogenic factors in the achievement or not of achieving pregnancy after ovarian stimulation. The methodology which was used is based on protein arrays and has produced promising prognostic tools in other studies, mainly related to carcinogenesis, although different biological features were exploited [20-23]. The basic biological material used in the study was the endometrial tissue which was collected from the patients the day of oocyte retrieval after ovarian stimulation. Endometrial tissue contains protein components which reliably reflect the biology of the endometrium. The inclusion of pro- and anti-angiogenic factors is in concert to the in vivo mechanisms of the angiogenic activity, which is the result of the balance between these two groups in the microenviroment of the endometrium, ensuring the cyclic variation during the menstrual cycle [24].

A total of 55 angiogenic factors have been examined and it demonstated that a combination of seven factors (TABLE 4), constitute an "angiogenic profile" which have been shown a strongest expression especially when pregnancy occurred. In literature rare similar studies have detected and correlated a higher pregnancy rate with the expression of specific individual angiogenic factors. In our study, for first time we examined 55 angiogenic factors simultaneously.

Angiogenin, is a pro-angiogenic growth factor which has mainly been studied in carcinogenesis. It is associated with cell apoptosis and survival through the p53 pathway [25]. Recent studies have highlighted the presence not only of angiogenin but also of VEGF (vascular endothelial growth factor) and bFGF in follicular fluid. The concentration of angiogenin in follicular fluid, have been associated with the maturity of the oocyte, attributed to the reduction of cell apoptosis which promote oocyte maturation [26]. Furthermore, other studies support that angiogenin has a pivotal role in ovarian hyperstimulation syndrome and in early gestation maintenance [27].
Endothelin (ET-1) is a polypeptide produced and released by the endothelial cells [28]. It's concentration in amniotic fluid is 10 to 100 times higher than in plasma [29]. Endothelin has been found in endometrium, amniotic fluid and amniotic membranes both in humans and animals [30]. Its role in human reproduction is not clear yet, although some studies support that that the presence of endothelin both in endometrium and embryo increase the chance of successful implantation and pregnancy [31]. Similar results related to the pregnancies have been described for the angiogenic factor Serpin-F1. Serpin, belongs to the inhibitors of proteolytic enzymes and it's concentration in endometrial tissue have been associated with the implantation of the trophoblast, the maintenance of pregnancy and the fetal growth $[32,33]$.

Some other angiogenic factors have also been associated with pregnancy and included in the final seven factors that compose the "angiogenic profile" of the endometrium. Platelet factor 4 (PF4) and Coagulation factor III, are produced by endometrial tissue and correlate with the recruitment of macrophages in the circular monthly endometrial remodeling, the interaction between endometrium and trophoblast, the implantation and the maintenance of pregnancy $[33,34]$. On the other hand, uPA (urokinase plasminogen activator) and TIMP-1 (tissue inhibitor of metalloproteinase-1), have been associated with "implantation window". The factor uPA, stimulates the production of specific enzymes by the emdometrial tissue, which promote the interaction between the endometrium and trophoblast and favor implantation [35,36]. TIMP-1, was found to be over expressed in endometrial period corresponding to the "implantation window" and promotes the production of enzymes that increase the receptivity of endometrium [3739]. Many other factors such as VEGF, HBEGF, FGF, and EG-VEGF were studied in our research and despite the fact that they are not included in the "angiogenic profile", are strongly correlated with pregnancy [39-47].

Technical issues such as local endometrial injury for tissue obtaining are unlikely to have affected our results. Endometrial injury to improve implantation for women undergoing assisted reproductive techniques has attracted a 
lot of attention recently and has rapidly become incorporated into clinical practice. Some studies demonstrate that endometrial scratching performed either during the spontaneous, preceding cycle, or during the IVF itself, significantly improve the rate of implantation, clinical pregnancies, and live births. These observations suggest that mechanical injury of the endometrium may enhance uterine receptivity by provoking the immune system to generate an inflammatory reaction. Recent findings suggest that a Th1 inflammatory response is necessary for the acquisition of uterine receptivity, while Th2-humoral inflammation is required for pregnancy maintenance. Other studies support that endometrial injury on the day of oocyte retrieval is associated with a reduction of clinical and ongoing pregnancy rates. Nevertheless, there are still no reliable researches to support these controversial views and for this reason we believe that our results have been not affected by the technique [48-63].

There are certain limitations associated with this report. The number of patients included was relatively low but this was due to the fact that the biological material that was used in the study was very difficult to be collected as we used endometrial tissue obtained in the day of oocyte retrieval. Furthermore, a commercially available kit was used because our intention was to leverage angiogenic profiling for eventual and widespread use in everyday practice. It is possible that other factors might also be useful but their study would complicate the practicability of this method. In spite of the limited number of patients, the results are remarkable as "angiogenic profile" of the 7 factors can not only separate the patients into 2 clusters but also classify the pregnancies in the same group, which means that a combination of angiogenic factors may contribute more than others to pregnancy achievement.

\section{Conclusion}

To the best of our knowledge, this is the first time that 55 angiogenic factors are studied simultaneously in endometrial tissue of women who undergoing ART, and are associated with pregnancy success. With the appropriate validation a combination of angiogenic factors could be used as predictive tool for ART outcome.

\section{List of Abbreviations}

ART : assisted reproduction techniques

IVF : in vitro fertilization

TNF-a: Tumor necrosis factor $-\mathrm{a}$

MCP: monocyte chemoattractant protein

PCA: Principal component analysis

FSH: Follicle stimulation hormone

LH: Luteinizing hormone

E2: Estradiol

PRL: Prolactin

TSH: Thyroid Stimulating Hormone

VEGF: vascular endothelial growth factor

ET-1: Endothelin

PF4: Platelet factor 4

uPA: urokinase plasminogen activator

TIMP-1: tissue inhibitor of metalloproteinase-1

\section{Acknowledgements}

Not Applicable.

\section{Ethics Approval and Consent to \\ Participate}

The study protocol had met appropriate Institutional Review Board approval ( $1^{\text {st }}$ Department of Obstetrics and Gynecology, Alexandra General Hospital, Athens, Greece) and written informed consent was given by all subjects for the collection and study of the endometrial tissue. The study was conducted according to the principles expressed in the declaration of Helsinki.

\section{Conflict of Interest}

The authors declare that they have no competing interests.

\section{Authors' Contributions}

Study Design: DL, S-P T, DM.

Acquisition of data: S-P T, GP

Analyzed the data: S-P T, EP, MM

Manuscript drafting: S-P T

Critically revision of Manuscript: DM, AC, GP, PD, S-P T.

Final approval: DL.

ALL authors read and approved the final manuscript 


\section{References}

Gurunath S, Pandian Z, Anderson $R A$, et al. Defining infertility-a systematic review of prevalence studies. Hum. Reprod. Update. 17(5), 575-588 (2011).

Behjati AZ, Akhondi MM, Mahmoodzadeh $\mathrm{H}$, et al. An evaluation of the historical importance of fertility and its reflection in ancient mythology. J. Reprod. Infertil. 17(1), 2-9 (2016).

Thonneau P, Spira A. Prevalence of infertility: international data and problems of measurement. Eur. J. Obstet. Gynecol. Reprod. Biol. 38(1), 43-52 (1991).

Thoma ME, McLain AC, Louis JF, et al. Prevalence of infertility in the United States as estimated by the current duration approach and a traditional constructed approach. Fertil Steril. 99(5),1324-1331 (2013).

Gianotten J, Lombardi MP, Zwinderman $\mathrm{AH}$, et al. Idiopathic impaired spermatogenesis: genetic epidemiology is unlikely to provide a short-cut to better understanding. Hum Reprod Update. 10(6), 533-539 (2004).

Templeton A, Morris JK, Parslow W. Factors that affect outcome of invitro fertilisation treatment. Lancet. 348(9039), 1402-6 (1996).

Tan SL, Royston P, Campbell S, et al. Cumulative conception and live-birth rates after in-vitro fertilization. Lancet. 339(8806), 1390-1394 (1992).

Michalas S, Loutradis D, Drakakis $\mathrm{P}$, et al. A flexible protocol for the induction of recipient endometrial cycles in an oocyte donation programme. Hum. Reprod. 11(5), 1063-6. (1996).

Loutradis D, Drakakis P, Dallianidis $\mathrm{K}$, et al. A double embryo transfer on days 2 and 4 or 5 improves pregnancy outcome in patients with good embryos but repeated failures in IVF or ICSI. Clin Exp Obstet Gynecol. 31(1), 63-6 (2004).

Kalmantis K, Loutradis D, Lymperopoulos E, et al. Three Dimensional Power Doppler evaluation of human endometrium after administration of oxytocine receptor antagonist (OTRa) in an IVF program. Arch Gynecol Obstet. 285(1), 265-70 (2012).

Beretsos P, Loutradis D, Koussoulakos $S$, et al. Oxytocin receptor is differentially expressed in mouse endometrium and embryo during blastocyst implantation. Ann. N Y Acad. Sci. 1092(1), 466-479 (2006).

Nardo LG, Sabatini L, Rai R, et al. Pinopode expression during human implantation. Eur J Obstet Gynecol. Reprod. Biol. 101(2), 104-108 (2002).

Nikas G, Drakakis P, Loutradis D, et al. Uterine pinopodes as markers of the 'nidation window' in cycling women receiving exogenous oestradiol and progesterone. Hum. Reprod. 10(5), 120813 (1995).

Rahiminejad ME, Moaddab A, Ebrahimi $M$, et al. The relationship between some endometrial secretion cytokines and in vitro fertilization. Iran J. Reprod. Med. 13(9), 557-562 (2015).

Liang PY, Diao LH, Huang CY, et al. The pro-inflammatory and anti-inflammatory cytokine profile in peripheral blood of women with recurrent implantation failure. Reprod. Biomed. Online. .31(6), 823-826 (2015).

Groeneveld E, Lambers MJ, Hoozemans DA, et al. Blood-borne angiogenic factors and sustained multiple implantation: a comparison of singleton and twin pregnancies. Reprod. Biomed. Online. 20(6), 822-30 (2010).

http://www.genetex.com/ uploaddata/Protocol/Document/ Cell\%20Lysate\%20Preparation.pdf.

https://www.rndsystems.com/ products/proteome-profiler-humanangiogenesis-array-kit_ary007

Lê S, Josse J, Husson F, et al. FactoMineR: An $R$ Package for Multivariate Analysis. J. Stat. Softw. 25(1), 1-18(2008).

Trachana SP, Pilalis E, Gavalas NG, et al. The Development of an Angiogenic Protein "Signature" in Ovarian Cancer Ascites as a Tool for Biologic and Prognostic Profiling. Plos One. 11(6), e0156403 (2016).

Korampalli TS, Green VL, Greenman $\mathrm{J}$, et al. Protein profiling of angiogenesisrelated growth factors in laryngeal carcinoma: Pattern of protein expression in relation to tumour progression. Int. J. Oncol. 39(4), 1033-1039 (2011)

Davidson B, Espina V, Steinberg SM, et al. Proteomic analysis of malignant ovarian cancer effusions as a tool for biologic and prognostic profiling. Clin. Cancer Res. 12(3 Pt 1), 791-799 (2006).

Peterson VM, Castro CM, Chung J, et al. Ascites analysis by a microfluidic chip allows tumor-cell profiling. Proc. Natl. Acad. Sci. U S A. 110(51), E497886 (2013).

Taylor RN, Lebovic DI, Hornung D, et al. Endocrine and paracrine regulation of endometrial angiogenesis. Ann. NY. Acad. Sci. 943, 109-121 (2001).

Sadagopan S, Veettil MV, Chakraborty $S$, et al. Angiogenin functionally interacts with $\mathrm{p} 53$ and regulates $\mathrm{p} 53$-mediated apoptosis and cell survival. Oncogene. 31(46), 4835-4847 (2012).

Malamitsi-Puchner A, Sarandakou A, Baka $S$, et al. In vitro fertilization: angiogenic, proliferative, and apoptotic factors in the follicular fluid. Ann. NY. Acad. Sci. 997, 124-128 (2003).

Molskness TA, Stouffer RL, Burry $\mathrm{KA}$, et al. Circulating levels of free and total vascular endothelial growth factor (VEGF)-A, soluble VEGF receptors-1 and -2 , and angiogenin during ovarian stimulation in non-human primates and women. Hum. Reprod. 19(4), 822-830 (2004)

Yanagisawa $\mathrm{M}$, Inoue A, Ishikawa $\mathrm{T}$, et al. Primary structure, synthesis, and biological activity of rat endothelin, an endothelium-derived vasoconstrictor peptide. Proc. Natl. Acad. Sci. U S A. 85(18), 6964-6967 (1988).

Casey ML, Brown CE, Peters M, et 
al. Endothelin levels in human amniotic fluid at mid-trimester and at term before and during spontaneous labor. J. Clin. Endocrinol. Metab. 76(6), 1647-1650 (1993).

Riley SC, Findlay JK, Salamonsen LA. Endothelin-1 and endothelin receptors are present in the sheep uterus and conceptus at implantation. J. Endocrinol. 147(2), 235-244 (1995).

Altmäe S, Reimand J, Hovatta $\mathrm{O}$, et al. Research resource: interactome of human embryo implantation: identification of gene expression pathways, regulation, and integrated regulatory networks. Mol. Endocrinol. 26(1), 203-217 (2012).

Floridon C, Nielsen O, Hølund B, et al. Does plasminogen activator inhibitor-1 (PAI-1) control trophoblast invasion? A study of fetal and maternal tissue in intrauterine, tubal and molar pregnancies. Placenta. 21(8):754-762 (2000).

Giudice LC. Growth factors and growth modulators in human uterine endometrium: their potential relevance to reproductive medicine. Fertil. Steril. 61(1), 1-17 (1994).

Ivanov P, Tsvyatkovska T, Konova $\mathrm{E}$, et al. Inherited thrombophilia and IVF failure: the impact of coagulation disorders on implantation process. Am. J. Reprod. Immunol. 68(3), 189-198 (2012).

Bulletti C, Flamigni C, de Ziegler D. Implantation markers and endometriosis. Reprod. Biomed.Online. 11(4), 464-468 (2005).

Bulletti C, de Ziegler D. Uterine contractility and embryo implantation. Curr. Opin. Obstet. Gynecol. 17(3), 265276 (2005).

Estella C, Herrer I, Atkinson SP, et al. Inhibition of histone deacetylase activity in human endometrial stromal cells promotes extracellular matrix remodelling and limits embryo invasion. PLoS One. 7(1), e30508 (2012).

Gao F, Wei P, Chen X, et al. Relationship between uterine expression of matrix metalloproteinases and their inhibitors and endometrial receptivity. Sci.
China C. Life Sci. 45(4), 406-411 (2002).

Wang N, Geng L, Zhang S, et al. Expression of PRB, FKBP52 and HBEGF relating with ultrasonic evaluation of endometrial receptivity. PLoS One. 7(3), e34010 (2012).

Baston-Buest DM, Porn AC, Schanz A, et al. Expression of the vascular endothelial growth factor receptor neuropilin-1 at the human embryo-maternal interface. Eur. J. Obstet. Gynecol. Reprod. Biol. 154(2), 151 156 (2011).

Lessey BA, Gui Y, Apparao KB, et al. Regulated expression of heparin-binding EGF-like growth factor (HB-EGF) in the human endometrium: a potential paracrine role during implantation. Mol. Reprod. Dev. 62(4), 446-455 (2002).

Wollenhaupt K, Welter H, Einspanier $\mathrm{R}$, et al. Expression of epidermal growth factor receptor (EGF-R), vascular endothelial growth factor receptor (VEGF-R) and fibroblast growth factor receptor (FGF-R) systems in porcine oviduct and endometrium during the time of implantation. J.Reprod. Dev. 50(3), 269-278 (2004).

Seo H, Choi Y, Shim J, et al. Regulatory mechanism for expression of IL1B receptors in the uterine endometrium and effects of IL1B on prostaglandin synthetic enzymes during the implantation period in pigs. Biol. Reprod. 87(2), 31 (2012).

Kawamura K, Chen Y, Shu Y, et al. Promotion of human early embryonic development and blastocyst outgrowth in vitro using autocrine/paracrine growth factors. PLoS One. 7(11), e49328 (2012).

Mittaz L, Russell DL, Wilson T, et al. Adamts- 1 is essential for the development and function of the urogenital system. Biol. Reprod. 70(4), 1096-1105 (2004).

Florio P, Bruni L, Galleri L, et al. Evaluation of endometrial activin $\mathrm{A}$ secretion for prediction of pregnancy after intrauterine insemination. Fertil. Steril. 93(7), 2316-2320 (2010).

Stoikos CJ, Salamonsen LA, Hannan NJ, et al. Activin A regulates trophoblast cell adhesive properties: implications for implantation failure in women with endometriosis-associated infertility. Hum. Reprod. 25(7), 1767-1774 (2010).

Legge A, Bouzayen R, Hamilton L, et al. The impact of maternal body mass index on in vitro fertilization outcomes. J. Obstet. Gynaecol. Can. 36(7), 613-619 (2014).

Sarais V, Pagliardini L, Rebonato G, et al. A Comprehensive Analysis of Body Mass Index Effect on in Vitro Fertilization Outcomes. Nutrients. 8(3), 109 (2016).

Wang X, Hao J, Zhang F, et al. Effects of female and male body mass indices on the treatment outcomes and neonatal birth weights associated with in vitro fertilization/intracytoplasmic sperm injection treatment in China. Fertil. Steril. 106(2), 460-466 (2016).

Shapiro BS, Daneshmand ST, Desai J, et al. The risk of embryo-endometrium asynchrony increases with maternal age after ovarian stimulation and IVF. Reprod. Biomed Online. 33(1), 50-55 (2016).

Yeh JS, Steward RG, Dude AM, et al. Pregnancy outcomes decline in recipients over age 44: an analysis of 27,959 fresh donor oocyte in vitro fertilization cycles from the Society for Assisted Reproductive Technology. Fertil. Steril. 101(5), 13311336 (2014).

Muto H, Yamamoto R, Ishii K, et al. Risk assessment of hypertensive disorders in pregnancy with maternal characteristics in early gestation: A single-center cohort study. Taiwan J. Obstet. Gynecol. 55(3), 341-345 (2016).

Gleicher $\otimes$, Kushnir VA, Sen A, et al. Definition by FSH, AMH and embryo numbers of good-, intermediate- and poorprognosis patients suggests previously unknown IVF outcome-determining factor associated with AMH. J.Transl. Med. 14(1), 172 (2016).

Busnelli A, Paffoni A, Fedele L, et al. The impact of thyroid autoimmunity on IVF/ICSI outcome: a systematic review and meta-analysis. Hum. Reprod. Update. 22(6), 775-790 (2016).

Sills ES, Alper MM, Walsh AP. Ovarian 
reserve screening in infertility: practical applications and theoretical directions for research. Eur. J. Obstet. Gynecol. Reprod. Biol. 146(1), 30-36 (2009).

Foroozanfard F, Moraveji SA, Taghavi SA, et al. Association Between Serum Estradiol Level on the Day of hCG Administration and IVF-ICSI Outcome. J. Obstet. Gynaecol. India. 66(3), 170-173 (2016).

Kitaya K, Matsubayashi H, Takaya $\mathrm{Y}$, et al. Clinical background affecting pregnancy outcome following local endometrial injury in infertile patients with repeated implantation failure. Gynecol. Endocrinol. 18, 1-4 (20160

Panagiotopoulou N, Karavolos S, Choudhary M. Endometrial injury prior to assisted reproductive techniques for recurrent implantation failure: a systematic literature review. Eur. J. Obstet. Gynecol. Reprod. Biol. 193, 27-33 (2015).

Nastri CO, Lensen SF, Gibreel A, et al. Endometrial injury in women undergoing assisted reproductive techniques. Cochrane Database Syst. Rev. 22(3), CD009517 (2015).
Simón C, Bellver J. Scratching beneath 'The Scratching Case': systematic reviews and meta-analyses, the back door for evidence-based medicine. Hum. Reprod. 29(8), 1618-1621 (2014).

Dekel N, Gnainsky Y, Granot I, et al. The role of inflammation for a successful implantation. Am. J. Reprod. Immunol. 72(2), 141-147 (2014).

Granot I, Gnainsky Y, Dekel N. Endometrial inflammation and effect on implantation improvement and pregnancy outcome. Reproduction. 144(6), 661-668 (2012). 